\title{
Current status of awareness, knowledge and attitude of dentists in palestine towards cone beam computed tomography: A survey
}

Emad Qirresh, Hakam Rabi and Tarek Rabi*

*Correspondence: tarekrabi@gmail.com

Department of Conservative dentistry and Dental Materials, Al Quds University, PO.Box 19759 - Jerusalem, Palestinian Territory.

\begin{abstract}
Objectives: Cone Beam Computed Tomography (CBCT) is being seen by many in dentistry as the standard imaging procedure for many dental implants, orthognathic, orthodontic, or endodontic cases. With this understanding, the purpose of this study was to assess the current state of knowledge, attitude and awareness of dentists in Palestine towards the usage of CBCT.

Materials and methods: An online questionnaire with 16 items on CBCT was mailed to 300 private practitioners registered with the Palestinian Dental Association. Also, the demographic details of the dentists such as name, gender, qualification, specialty and years of experience were collected. The collected data was analyzed and then subjected to descriptive statistical analysis.

Results: 176 dentists responded to this questionnaire, 110 dentists did not respond, and communication could not be established with 14 dentists. All the participants were aware of CBCT and felt that its usage should be increased in dental radiology, and more workshops should be held to provide information related to CBCT.

Conclusion: Cone beam computed tomography is a relatively advanced imaging technique with a profound potential in the field of dentistry. This fact is now being realized and accepted by most of the dental specialists. The study results indicate that there is a definite gap in knowledge of CBCT applications amongst the dental specialists.
\end{abstract}

Keywords: Awareness, cone bean computed tomography, knowledge, dental radiology

\section{Introduction}

Technological advances, such as digital imaging systems have significantly increased the level of detailed information available to practitioners while mitigating the level of patient radiation exposure [1]. While oral health professionals have long relied on 2-D imaging for diagnosis and treatment planning, this technology typically requires multiple exposures, and with them, multiple doses of harmful radiation [2]. Today, with a properly prescribed 3-D scan, practitioners have gained the ability to collect much more data-often with a single scan and potentially with a lower effective patient dose [3].

Cone beam computed tomography (or $\mathrm{CBCT}$, also referred to as $\mathrm{C}$-arm $\mathrm{CT}$, cone beam volume $\mathrm{CT}$ or flat panel $\mathrm{CT}$ ) is a medical imaging technique consisting of $\mathrm{X}$-ray computed tomography where the X-rays are divergent, forming a cone [4]. Cone beam technology was first introduced in the European market in 1996 by QR S.R.L. (NewTom 9000) and into the US market in 2001 [4]. This type of CT scanner uses a special type of technology to generate three-dimensional (3-D) images of dental structures, soft tissues, nerve paths and bone in the craniofacial region in a single scan [5]. The images obtained with the cone beam $\mathrm{CT}$ allow for more precise treatment planning.

With cone beam CT, an X-ray beam in the shape of a cone is moved around the patient to produce large number of images in the form of views or slices. CT scans and cone beam CT both produce high-quality images [6]. One benefit of this technology is its ability to provide sub-millimeter resolution in terms of images. The images provided are also high in diagnostic 
quality. CBCT is a popular choice among dental professionals because of its short scanning period. It only takes about 10 to 70 seconds to complete the scan [6].

Radiation dosages were also reported to being 15 times lower than conventional CT scans. Increased utilization of this system can help dental clinicians in receiving imaging modalities that have the capacity of offering three-dimensional (3-D) representation of a patient's maxillofacial skeleton. CBCT performs this function with the least amount of distortion and it is a truly useful system for numerous professionals practicing dentistry [6].

Significantly increased usage of $C B C T$ was evidenced by a recent web-based survey of active AAE members in the United States and Canada, which found that $34.2 \%$ of 3,844 respondents employed CBCT in their clinical practices. The survey concluded that CBCT was most frequently used for the diagnosis of pathologies, as a preparation for endodontic treatment or endodontic surgery, and as an adjunct in the diagnosis of trauma-related injuries.

$\mathrm{CBCT}$, as with any technology, has known limitations. The patient's history and clinical examination must justify the use of CBCT by demonstrating that the benefits to the patient outweigh the potential risks. Clinicians should use CBCT only when the need for imaging cannot be answered adequately by lower dose conventional dental radiography or alternate imaging modalities [7]. There are also numerous CBCT equipment manufacturers and models available. In general, CBCT can be categorized into large-, medium- and limited-volume units based on the size of their "field of view" [8,9].

Globally, there is a recent increase in the application of CBCT in various fields of dentistry and it is a necessity that the dentist should be aware of it. Hence, the present study was designed with an aim to assess the current knowledge and awareness among the dentists in Palestine towards the usage and application of CBCT.

\section{Materials and methods}

An online questionnaire was mailed to 300 practitioners registered with Palestinian dental association. Among 300 participants, 176 dentists responded, 110 did not respond back, and 14 dentists could not be contacted. Out of the 176 dentists who participated in the study, 56.8\% (100) were females and $43.2 \%$ (76) were males (Table 1 ).

The self-administered questionnaire also included the demographic details of the participant such as their qualification, designation, specialty, the duration of their experience. Based on the review of the literature and few existing curricula,

Table 1. Gender and 'years in practice' of the study participants.

\begin{tabular}{lllll}
\hline Participants & Less than 5 & $\begin{array}{l}\text { 6-9 years } \\
\text { Males }\end{array}$ & $\begin{array}{l}\text { More than } \\
\text { 10 years }\end{array}$ & Total \\
\hline Females & 15 & 36 & 25 & 76 \\
\hline
\end{tabular}

a total of 16 items or topics in CBCT were identified and included in the same questionnaire. It acted as the initial stage of consensus development where the participants were asked to select from the given options. Questions such as the awareness about the imaging modality, its usefulness and reasons for its preference were included in this questionnaire. A reminder was given to the participants after one month for the completion of the questionnaire. The data collected was sorted, tabulated, and analyzed in lieu of the objectives of the study, using descriptive analysis.

\section{Results}

The initial questions were aimed to assess the primary knowledge regarding the usage of digital imaging, to which $90.9 \%$ (160) responded that they have used the digital imaging either in their clinics or at a radiology center, whereas $9.1 \%$ (16) said that they did not use any digital imaging in their practice. All the study participants (100\%) were aware about the usage of CBCT in dentistry. Additionally, the source of knowledge regarding CBCT was queried and a very high fraction of subjects (122) chose continuing dental education whereas, the remainder acquired the knowledge from their college. To further that, all the participated dentists $100 \%$ (176) agreed upon the statement that CBCT was a useful diagnostic tool in dentistry. About its future in dentistry, 90.9\% (160), dentists believed that CBCT will be the ultimate imaging tool in a clinician's hands in the future years. All the dentists $100 \%$ (176) agreed to the fact that CDE and workshops should be conducted at regular intervals to provide information regarding $C B C T$ and that every dental institution must possess $C B C T$ equipment. Most of the participants 56\% (100) observed that adequate education about CBCT was not being imparted to the undergraduates in their dental colleges. Majority of the dentists preferred CBCT imaging over CT scan when 3D imaging is required and $83 \%$ responded that they have advised $\mathrm{CBCT}$ in the treatment protocol (Table 2).

Table 2. Opinion of participants showing their knowledge towards CBCT.

\begin{tabular}{|c|c|c|}
\hline Questions & Yes & No \\
\hline Do you use digital imaging & 160 & 16 \\
\hline Are you aware of CBCT use in Dental Radiology & 176 & 0 \\
\hline Did you come across term CBCT & 176 & 0 \\
\hline Do you feel CBCT is a diagnostic tool in dentistry? & 176 & 0 \\
\hline $\begin{array}{l}\text { Do you feel CBCT will be the tool of future in } \\
\text { dentistry? }\end{array}$ & 160 & 16 \\
\hline $\begin{array}{l}\text { Do you feel the need of workshops and CDE for } \\
\text { CBCT? }\end{array}$ & 176 & 0 \\
\hline $\begin{array}{l}\text { Do you feel the necessity of installation of CBCT in } \\
\text { Dental institutions }\end{array}$ & 176 & 0 \\
\hline $\begin{array}{l}\text { Is adequate teaching is given to the dental students } \\
\text { regarding CBCT by the faculties of the college? }\end{array}$ & 76 & 100 \\
\hline Have you attended any courses related to CBCT? & 16 & 160 \\
\hline Have you ever advised CBCT for diagnosis? & 30 & 146 \\
\hline
\end{tabular}


Following which, the reason towards the usage of digital imaging in routine practice was raised in the questionnaire. $36.4 \%$ (64) dentists specifically gave the reason of less radiation dosage, $27.3 \%$ (48) chose 'result obtained in short duration', whereas $9.1 \%$ (16) dentists opted for multiple reasons like less radiation dosage, ease of adjustment and measurement. A smaller proportion of dentists $4.5 \%$ (8) gave the reason of less radiation dosage as well as short time to get results. and $8.5 \%$ (15) of the study population opted for ease of data storage in addition to less radiation dosing and ease of adjustment \& measurement. Lastly $4 \%$ (7) dentists chose multiple options including ease of adjustment and measurement and 1.1\% (2) opted for lower radiation dosage and shorter duration for result. It was confounding to note to that $90 \%$ of the participants had not attended any courses related to the CBCT (Table 3).

Regarding the usage of $C B C T$, maximum percentage of dentists (27.3\%) preferred using CBCT for endodontic and dental implant procedures whereas a small population opted for the diagnosis of pathoses, impacted teeth etc (Table 4).

Table 3. Reasons Specific for the use of digital imaging.

\begin{tabular}{ll}
\hline Various Reasons & No. \\
\hline Less radiation dosage & 64 \\
$\begin{array}{l}\text { Short time } \\
\text { Less radiation dose \& Ease of adjustments and }\end{array}$ & 48 \\
measurements & 16 \\
$\begin{array}{l}\text { Less radiation dosage \& short result time } \\
\text { Less radiation dosage, ease to store data, Ease of }\end{array}$ & 15 \\
$\begin{array}{l}\text { adjustments and measurements } \\
\text { Less radiation dosage, ease to store data, Ease of } \\
\text { adjustments and measurements }\end{array}$ & 2 \\
$\begin{array}{l}\text { Less radiation dosage, short time, ease to store data, } \\
\text { Ease of adjustments and measurements }\end{array}$ & 7 \\
\hline
\end{tabular}

Table 4. Usage of CBCT in dental field.

\begin{tabular}{ll}
\hline Various Fields & No. \\
\hline Implants & 16 \\
Evaluation of cyst \& tumors & 16 \\
Endodontic cases & 48 \\
Implants \& endodontic cases & 48 \\
Implants \& evaluation of impacted teeth & 16 \\
Implants \& evaluation of cyst \& tumors & 16 \\
Implants, endodontic cases, evaluation & 16 \\
$\begin{array}{l}\text { of impacted teeth, evaluation of cyst \& } \\
\text { tumors }\end{array}$ & \\
\hline
\end{tabular}

\section{Discussion}

Like many other new technologies, which have progressed from the extraordinary to the ordinary and thus gained acceptance by professionals and patients, CBCT has advanced from exceptional use to a common imaging modality in dentistry due to depreciating cost, easy access to the technology, and attenuated radiation exposure to the patient. Today, CBCT is seen by many in dentistry as the standard imaging procedure for dental implants, orthognathic, orthodontic, and endodontic cases [10]. However in our study maximum percentage of the dentists preferred to use it in implant and endodontic cases only. The results are in accordance with the study conducted by Shetty SR et al., (2015) [11] and Balabaskaran K et al. (2013).

CBCT scanning delivers an effective dose approximately 50 to 100 times less than the radiation dose delivered during conventional $C T$. Evidence suggests that $\mathrm{CBCT}$ offers a precise and detailed evaluation of implant site by providing accurate cross-sectional imaging and 3-dimensional visualization of anatomic structures, at a relatively lower and safer dose.

Owing to these advantages $90.9 \%$ of the dentist in our study agreed to the usage of $C B C T$ in routine practice. The result is very much contradicting to studies by (Beason and Brooks) [12] and Balabaskaran $\mathrm{K}$ et al., (2013), in which more than $90 \%$ of the dentists had never used CBCT and $65 \%$ had never used conventional tomography. CBCT technology is becoming more widely available and less costly; $C B C T$ scanners are available from most dental $\mathrm{X}$-ray equipment manufacturers in a wide variety of formats with various attributes. For the most part, the patient is examined standing or seated, and the machines have the footprint (though not necessarily the capability) of a panoramic unit.

Some of the questions in the questionnaire were specifically designed to assess the practitioner's knowledge regarding $\mathrm{CBCT}$. Our study concluded that all the participants were aware of the usage of $C B C T$ in dental radiology, and also they found it to be a useful diagnostic tool in dentistry as well as in future perspectives. However, $54.5 \%$ dentists did not prefer CBCT for routine usage owing to its expense, whereas $9 \%$ of the subjects presented with lack of computer knowledge required for CBCT application. This is in accordance with Shetty SR et al., [11] results of the study done in 2015 and contradicting to the study done by Ramakrishnan P. et al., in 2014 [13] in which primary reasons were broad coverage of facial bones and teeth (65.3\%), followed by measurement precision (7.3\%), availability (5.7\%), cost (1.7\%) and patient radiation dose (1\%).

CBCT has also been recognized by general dentists and specialists as a means by which they can separate, identify, and distinguish their practices as being on the vanguard of technology in patient care. Today's patients expect their dentist and physicians to be contemporary with technology and services. CBCT provides the doctor with technology, which not only has significant advantages in treating patients but also has a noteworthy "wow" factor as the 3-D images are seen on a large screen in "real time" for the doctor and patient to view.

The creation of the newest ADA specialty, oral and maxillofacial radiology, and the advent of many cone beam radiography devices on the market have made a significant impact on dentistry. Until a few years ago, the presence of 3-D radiography was relatively unknown and unused in dentistry. Now, dentists are inundated with articles, research, advertisements, and salespeople promoting cone beam radiography. Neverthe- 
Qirresh et al. Oral Biology and Dentistry 2016,

http://www.hoajonline.com/journals/pdf/2053-5775-4-1.pdf

doi: $10.7243 / 2053-5775-4-1$

less, a vast majority of the dentists in this study observed that adequate knowledge related to $\mathrm{CBCT}$ usage was not being provided in the educational institutions. In order to fill the lacuna, they suggested that CDE programs and seminars on the basic aspects of CBCT should be conducted and is the need of the hour for current and future practitioners in Palestine. These results are in accordance with the study done by Balabaskaran K et al., 2013 and Aditya A et al. 2015 [14].

Cone beam CT provides detailed images of the bone and is performed to evaluate diseases of the jaw, dentition, and bony structures of the face, nasal cavity and sinuses. It does not provide the full diagnostic information available with conventional $\mathrm{CT}$, particularly in the evaluation of soft tissue structures such as muscles, lymph nodes, glands, and nerves. However, cone beam CT has the advantage of lower radiation exposure compared to conventional CT. Dental CBCT systems have been sold in the United States since the early 2000s and are increasingly used by radiologists and dental professionals for various clinical applications including dental implant planning, visualization of abnormal teeth, evaluation of the jaws and face, cleft palate assessment, diagnosis of dental caries (cavities), endodontic (root canal) diagnosis, and diagnosis of dental trauma [15]. In our study, maximum percentage of dentists owed the use of CBCT for implant and endodontic cases which is in accordance to the research done by Kamburoglu et al. (2011) [16].

The limitations of this study include its self-reporting questionnaire which has the potential to induce bias, the sampling which could have included the student population and the sample size as the results cannot be generalized. However, the consensus obtained from this study on the general need of the dental practitioners to have a formal and structured training in $\mathrm{CBCT}$ cannot be overlooked.

\section{Conclusion}

The awareness of dental practitioners to newer and safer imaging modalities is essential for disseminating whole some patient care. Even though the awareness of CBCT usage was high among the dentists, there was inadequate knowledge and training towards its skilful utilization. This study concludes by stressing that CDE programs and workshops need to be organized on a routine basis in order to update and motivate the dentists towards efficient practice regimens.

\section{Competing interests}

The authors declare that they have no competing interests.

Authors' contributions

\begin{tabular}{|l|c|c|c|}
\hline Authors' contributions & EQ & HR & TR \\
\hline Research concept and design & $\checkmark$ & $\checkmark$ & $\checkmark$ \\
\hline Collection and/or assembly of data & $\checkmark$ & $\checkmark$ & $\checkmark$ \\
\hline Data analysis and interpretation & $\checkmark$ & $\checkmark$ & $\checkmark$ \\
\hline Writing the article & $\checkmark$ & $\checkmark$ & $\checkmark$ \\
\hline Critical revision of the article & $\checkmark$ & $\checkmark$ & $\checkmark$ \\
\hline Final approval of article & $\checkmark$ & $\checkmark$ & $\checkmark$ \\
\hline
\end{tabular}

\section{Acknowledgement}

Thanking the Palestinian dentists who participated in this study.

Publication history

Editors: Cássio do Nascimento, University of Sao Paulo, Brazil.

Lawrence Gettleman, University of Louisville, USA.

Received: 31-May-2016 Final Revised: 04-Jul-2016

Accepted: 18-Jul-2016 Published: 28-Jul-2016

\section{References}

1. Lillesand T, Kiefer RW and Chipman J. Remote sensing and image interpretation. John Wiley \& Sons. 2014.

2. Geleijns $J$ and Broerse JJ. [Radiation risks in dental and medical radiography]. Ned Tijdschr Tandheelkd. 1995; 102:484-7. | Article | PubMed

3. Rugani P, Kirnbauer B, Arnetzl GV and Jakse N. Cone beam computerized tomography: basics for digital planning in oral surgery and implantology. Int J Comput Dent. 2009; 12:131-45. | PubMed

4. Scarfe WC, Farman AG and Sukovic P. Clinical applications of cone-beam computed tomography in dental practice. J Can Dent Assoc. 2006; 72:7580. | Article | PubMed

5. Kiljunen T, Kaasalainen T, Suomalainen A and Kortesniemi M. Dental cone beam CT: A review. Phys Med. 2015; 31:844-60. | Article | PubMed

6. Hatcher DC. Operational principles for cone-beam computed tomography. J Am Dent Assoc. 2010; 141 Suppl 3:3S-6S. | Article | PubMed

7. White SC. Cone-beam imaging in dentistry. Health Phys. 2008; 95:62837. | Article | PubMed

8. Al-Nazhan SA. Endodontic Update.

9. Nainan MT, Koshy S, Naveen D, Benjamin S, Murali R, Guru R and Ashok $\mathrm{K}$. CBCT in Diagnosis of Vertical Root Fracture. Journal of Indian Academy of Oral Medicine and Radiology. 2012; 24:311-4. | Pdf

10. Orth RC, Wallace MJ, Kuo MD and C-arm cone-beam CT. general principles and technical considerations for use in interventional radiology. Journal of Vascular and Interventional Radiology. 2008; 19:814-20. | Pdf

11. Shetty S, Castelino R, Babu S, Prasanna LA and Roopashri K. Knowledge and Attitude of Dentists towards Cone Beam Computed Tomography in Mangalore-A Questionnaire Survey. Austin J Radiol. 2015; 2:1016.

12. Beason $R$ and Brooks S. Preoperative implant site assessment in southeast Michigan. J Dent Res. 2001; 80:137.

13. Ramakrishnan P, Shafi FM, Subhash A, Kumara A, Chakkarayan J and Vengalath J. A survey on radiographic prescription practices in dental implant assessment among dentists in Kerala, India. Oral Health Dent Manag. 2014; 13:826-30. | Pdf | PubMed

14. Aditya A, Lele $S$ and Aditya P. Current status of knowledge, attitude, and perspective of dental practitioners toward cone beam computed tomography: A survey. Journal of Oral and Maxillofacial Radiology. 2015; 3:54. | Article

15. Miracle AC and Mukherji SK. Conebeam CT of the head and neck, part 2: clinical applications. AJNR Am J Neuroradiol. 2009; 30:1285-92. | Article I PubMed

16. Kamburoglu K, Kursun S and Akarslan ZZ. Dental students' knowledge and attitudes towards cone beam computed tomography in Turkey. Dentomaxillofac Radiol. 2011; 40:439-43. | Article | PubMed Abstract | PubMed FullText

\section{Citation:}

Qirresh E, Rabi H and Rabi T. Current status of awareness, knowledge and attitude of dentists in palestine towards cone beam computed tomography: A survey. Oral Biol Dent. 2016; 4:1.

http://dx.doi.org/10.7243/2053-5775-4-1 